\title{
FEATURES AND ADVANTAGES OF THE PROCESS OF FRICTION STIR WELDING OF BUTT JOINTS OF SHEET ALUMINIUM-LITHIUM ALLOYS
}

\author{
A.G. POKLYATSKY, V.V. KNYSH, I.N. KLOCHKOV and S.I. MOTRUNICH \\ E.O. Paton Electric Welding Institute, NASU \\ 11 Kazimir Malevich Str., 03680, Kiev, Ukraine. E-mail: office@paton.kiev.ua
}

\begin{abstract}
The paper analyzes the structural features, strength and fatigue life properties of sheet joints of Al-Li alloys 1420 and 1460 , produced by nonconsumable-electrode argon-arc welding and friction stir welding. It is shown that application of FSW provides formation of permanent joints with minimum level of stress concentration in the points of weld transition to base material and allows avoiding defects in welds in the form of pores, oxide film macroinclusions or hot cracks due to melting and solidification of metal in fusion welding. Here, intensive plastic deformation of metal under the tool shoulder and in weld nugget results in formation of fine-crystalline $(3-4 \mu \mathrm{m})$ uniform disoriented structure, and grain elongation and distortion in the direction of plasticized metal displacement proceed in adjacent sections. This leads to increase of hardness and ultimate strength of joint weld metal. Lowering of the temperature of heating of the edges being welded provides reduction of maximum level of tensile residual longitudinal stresses in welded joints, compared to TIG welding. It is found that fatigue resistance characteristics of butt welded joints, made by FSW, are superior to those of the joints, made by TIG welding. 10 Ref., 9 Figures.
\end{abstract}

Keywords : Al-Li alloys, friction stir welding, defects, microstructure, ultimate strength, fatigue resistance

Application of high-strength corrosion-resistant AlLi alloys, characterized by lower density and high modulus of elasticity, allows reducing fuel consumption and improving tactico-technical characteristics of aerospace engineering products. Developed in 1968 by a team led by I.N. Fridlyander, 1420 alloy (density of $2.4 \mathrm{~g} / \mathrm{cm}^{3}$ ) of $\mathrm{Al}-\mathrm{Mg}-\mathrm{Li}$ alloying system containing $4.5-6.0 \% \mathrm{Mg}$ and $1.8-2.3 \% \mathrm{Li}$, has by $12 \%$ lower specific weight and $8 \%$ higher modulus of elasticity than D16 alloy, extensively applied in aircraft construction. Its application in riveted structure of fuselage of vertical takeoff aircraft Yak-36 provided a weight gain of $16 \%$. In 1980 the alloy was recommended for creation of world's first welded aircraft MiG-29 [1, 2].

The strongest $\left(\sigma_{t}>500 \mathrm{MPa}\right.$ at $2.6 \mathrm{~g} / \mathrm{cm}^{3}$ density) is 1460 alloy of $\mathrm{Al}-\mathrm{Cu}-\mathrm{Li}$ system (nominal composition of $3 \% \mathrm{Cu}$ and $2 \% \mathrm{Li}$ ) with zirconium and scandium additives. High values of strength and ductility of this alloy at superlow temperatures are indicative of the good prospects for its application in manufacture of welded cryogenic tanks [3].

To produce permanent joints of aluminium alloys, various fusion welding processes are applied in the majority of cases, in which the weld forms as a result of melting of a certain volume of materials being joined and filler wire in a common weld pool with their subsequent solidification in shielding inert gas. However, in fusion welding of semi-finished products from Li-containing aluminium alloy, structural trans- formations proceed in weld metal and adjacent sections with formation of characteristic defects in the form of pores at application of base material strips as filler wire, and of extended filamentous macroinclusions of oxide film when filler wire is used. This necessitates application of technological measures, aimed at improving the quality of preparation of surfaces being welded and promoting intensification of weld pool metal stirring and activation of the processes of oxide film breaking up. Here, welded joint strength does not exceed 70-75\%, and weld metal strength $-65 \%$ of this value for base material $[4,5]$.

Application of FSW allows avoiding metal melting in the zone of weld formation and maximally preserving in welded components the properties of semi-finished products applied in their manufacture. In such welding weld formation proceeds in the solid phase, as a result of heating of a small metal volume to plastic state through friction, its stirring across the entire thickness of edges being welded and deformation in a closed space. Due to this, FSW process has several essential advantages, compared to fusion welding. Formation of fine-crystalline weld structure, lowering of the level of softening of materials being joined, preservation of alloying elements, absence of characteristic defects and improvement of joint mechanical properties are among them [6-9].

The objective of this work is establishing the advantages of FSW process, compared to TIG welding, when producing butt joints of Al-Li alloys 1420 and 1460 . 
Sheets of Al-Li alloys $14201.8 \mathrm{~mm}$ thick and $14602 \mathrm{~mm}$ thick were used for investigations. Butt joints were produced by TIG welding in MW-450 unit («Fronius», Austria) at the speed of $20 \mathrm{~m} / \mathrm{h}$ and current of 140-150 A, using strips from the respective base material as filler wire (for preservation of weld metal composition similar to base material), and respective filler wires SvAMg63 and Sv1201 of $1.6 \mathrm{~mm}$ diameter. FSW process was implemented in a laboratory unit, developed at PWI, using a special tool [10] with rotation speed of $1420 \mathrm{rpm}$ and linear displacement speed of $13-14 \mathrm{~m} / \mathrm{h}$.

Sections were cut out of the produced welded joints to study the structure, and samples with $15 \mathrm{~mm}$ width of the working part were prepared to determine the ultimate strength at uniaxial tension in keeping with GOST 699-66. Width of sample working part for determination of fatigue resistance was $25 \mathrm{~mm}$. Mechanical testing of samples was conducted in MTS 318.25 versatile servohydraulic complex. Cyclic testing was performed at axial regular loading with coefficient of stress cycle asymmetry $R_{\sigma}=0.1$ and frequency of $15 \mathrm{~Hz}$ up to complete fracture of samples. A series of 5-7 similar samples was tested at the same conditions. Experimental data of fatigue testing were processed by the methods of linear regression analysis, generally accepted for this type of testing. Results of performed testing were used to plot for each sample series, proceeding from limited endurance limits, the appropriate fatigue curve - a line of regression of experimental data in $2 \sigma_{a}-\lg N$ coordinates.

Metal hardness was measured on face surface of scraped joints. Degree of metal softening in the welding zone was assessed in Rockwell instrument at the load $P=600 \mathrm{~N}$. Assessment of structural features of welded joints was performed with application of optical electron microscope MIM-8. Residual longitudinal stresses in welded joints were determined experimentally by cutting method.

As a result of conducted investigations it was found that the mechanism of permanent joint formation in FSW differs essentially from the processes, occurring in fusion welding.

During FSW the weld forms as a result of heating due to friction up to plastic state, stirring and intensive deformation of a small volume of metal of the parts being joined by a special tool in a closed space, without application of shielding gas or filler material. At the initial stage of the welding process, the rotating tool tip gradually plunging into the butt ousts a certain volume of plasticized metal. This metal can move only around the tip or rise upwards, as its movement is limited by backing from below, and by non-plasticized base material from the side. Further immersion of the tool leads to full contact of working end face of its shoulder with the material being welded and creates completely confined space, which is where plasticized metal displacement occurs by a complex trajectory, determined by the configuration of working surfaces of the tool tip and shoulder. Now, when the instrument starts performing also translational motion, in addition to rotational motion, a zone of excess pressure forms ahead of its tip from the tool advancing side (where directions of vectors of rotation and linear displacement of the tool coincide), from which this pressure ousts a thin interlayer of plasticized metal towards the retreating side (opposite side, where the above vectors have different directions). Then, heated metal under pressure is pressed between the metal being welded and tool side surface from the retreating side into the space, vacated behind it, which forms as a result of the tool linear displacement. This leads to formation of a specific structure of welded joints (Figure 1) with a pronounced nugget (D), which is the result of dynamic recrystallization. Adjacent to it is the zone of thermomechanical impact (C), in which the metal was subjected to plastic deformation. Next comes the HAZ (B), where structural changes of base metal (A) are caused just by temperature rise.

Weld dimensions at FSW are smaller, and its shape differs advantageously from that produced by TIG welding: there is no weld reinforcement, which in fusion welding forms due to filler wire, and no through-thickness penetration, which is due to application of a backing with forming groove (Figure 2). This allows avoiding any significant stress concentration in the points of weld transition to base material, negatively affecting the operational and life characteristics of the joints. More over, formation of permanent joints in the solid phase will allow avoiding defects characteristic for these alloys: pores and macroinclusions of oxide film, formed in fusion welding. Absence of molten metal, in which hydrogen solubility rises abruptly, prevents additional saturation of

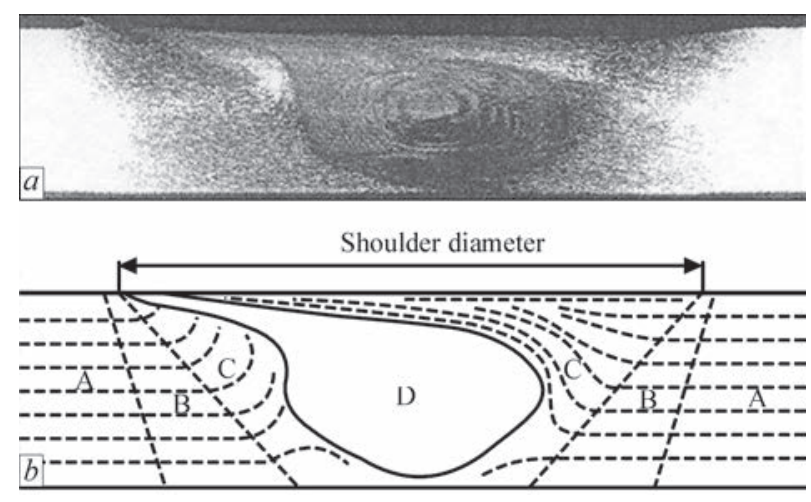

Figure 1. Transverse macrosections of FS-welded joint $(a)$, and schematic image of its characteristic zones $(b)$ (for zone description see the text) 


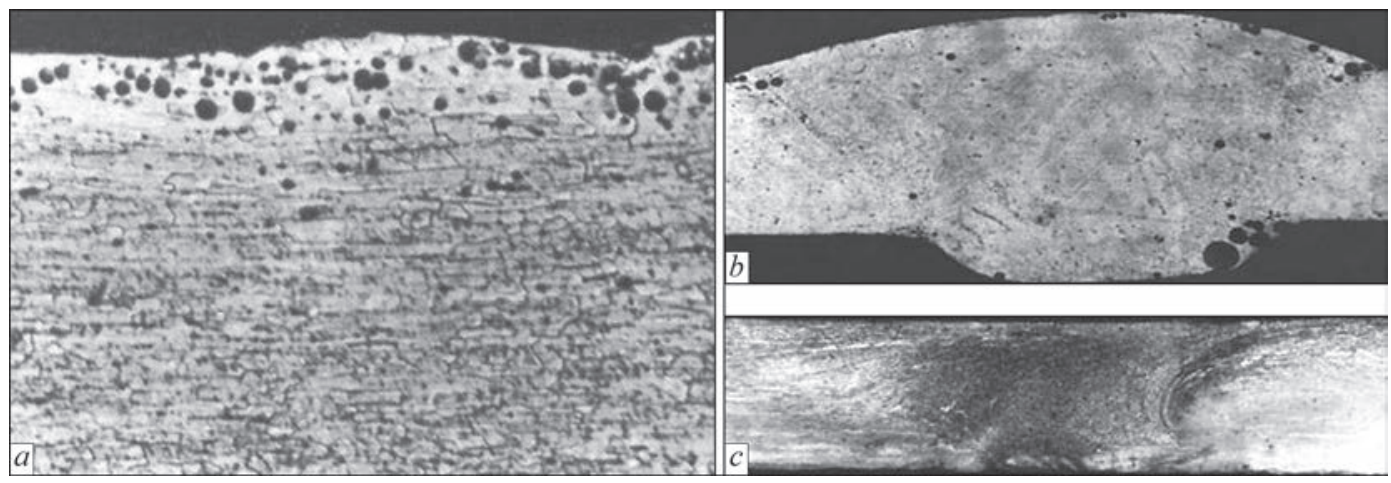

Figure 2. Microstructure $(\times 250)$ of subsurface layer of the sheet $(a)$ and cross-section of welds of 1420 alloy $1.8 \mathrm{~mm}$ thick produced by TIG welding $(b)$ and FSW $(c)$

welding zone by it due to migration of this gas from the adjacent gas-saturated surface layers of metal.

Intensive deformation and stirring of plasticized metal over the entire thickness of edges being welded promotes breaking up of oxide films present on them. Absence of molten metal in the zone of joint formation allows avoiding its oxidation during welding. Therefore, FS-welds do not have any defects in the form of either isolated or extended macroinclusions of oxide film, characteristic for welds made by TIG welding on Al-Li alloys (Figure 3).

Analysis of microstructure of Al-Li alloys welded joints showed that at TIG welding of 1460 alloy overheating and recrystallization regions are found in the HAZ near the fusion line (Figure 4). Extent of the zone of melting of the structure constituents is equal to about $2.25 \mathrm{~mm}$ from the fusion line. In the HAZ grains directly adjacent to this boundary have the largest size. Weld metal is characterized mainly by fine-crystalline structure. However, individual fragments of the central crystallite are observed in some of its sections. Near the boundary of fusion with the

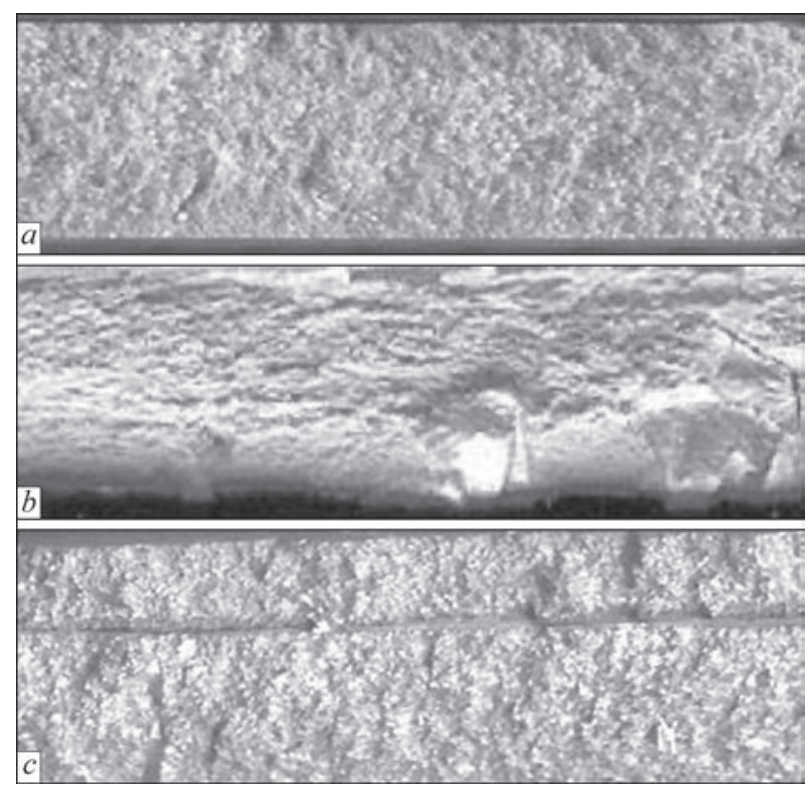

Figure 3. Longitudinal fractures of welds of 1460 alloy $2 \mathrm{~mm}$ thick, produced by FSW $(a)$ and TIG welding, with isolated $(b)$ and extended $(c)$ oxide film macroinclusions base material, an interlayer of fine subdendritic structure is visible in the weld (Figure 4, $b-d$ ).

In FSW of this alloy, the metal smoothly changes its grain orientation in thermomechanical impact zone in the direction of tool working surfaces displacement. It results in formation in this zone of extended elongated grains, oriented along the path of tool displacement, and fine equiaxed grains. In the weld central part (nugget), fine $(3-5 \mu \mathrm{m})$ equiaxed grains form as a result of considerable plastic deformation (Figure 4, $e-g$ ).

In FSW the degree of metal softening is smaller than in TIG welding, owing to lowering of edge heating temperature and formation of fine-crystalline weld structure. So, for 1420 alloy minimum hardness in the weld and zones of its transition to base metal is on the level of HRB 86-87. On the other hand, in TIG welding of 1420 alloy with filler wire SvAMg63, minimum metal hardness in the weld central part is just $H R B$ 81, and in fusion zones it is $H R B 89$ (Figure 5). Therefore, at tension of samples of joints with weld reinforcement, produced by fusion welding, fracture is localized in the zone of weld fusion with base material, and ultimate strength is equal to $373 \mathrm{MPa}$. Similar samples with removed reinforcement fail in weld center and have the ultimate strength of about $319 \mathrm{MPa}$. Ultimate strength of FS-welded joints, in which weld reinforcement is absent and which fail in the region of weld transition to base metal, is equal to $343 \mathrm{MPa}$. The same strength level is observed for joints with weld reinforcement, produced by TIG welding using a strip from 1420 base material as filler wire.

Measurements of metal hardness in the zone of permanent joint formation showed that in FSW of 1460 alloy hardness is also much higher than in TIG welding. In the weld and zones of weld to base metal transition, hardness is on the level of HRB 85-86, whereas in TIG welding with Sv1201 filler wire, minimum weld hardness in weld central part is HRB 71 and in the zones of weld fusion with base material it is HRB 82-83 (Figure 6).

Therefore, at uniaxial static tension, samples of such TIG-welded joints without weld reinforcement 


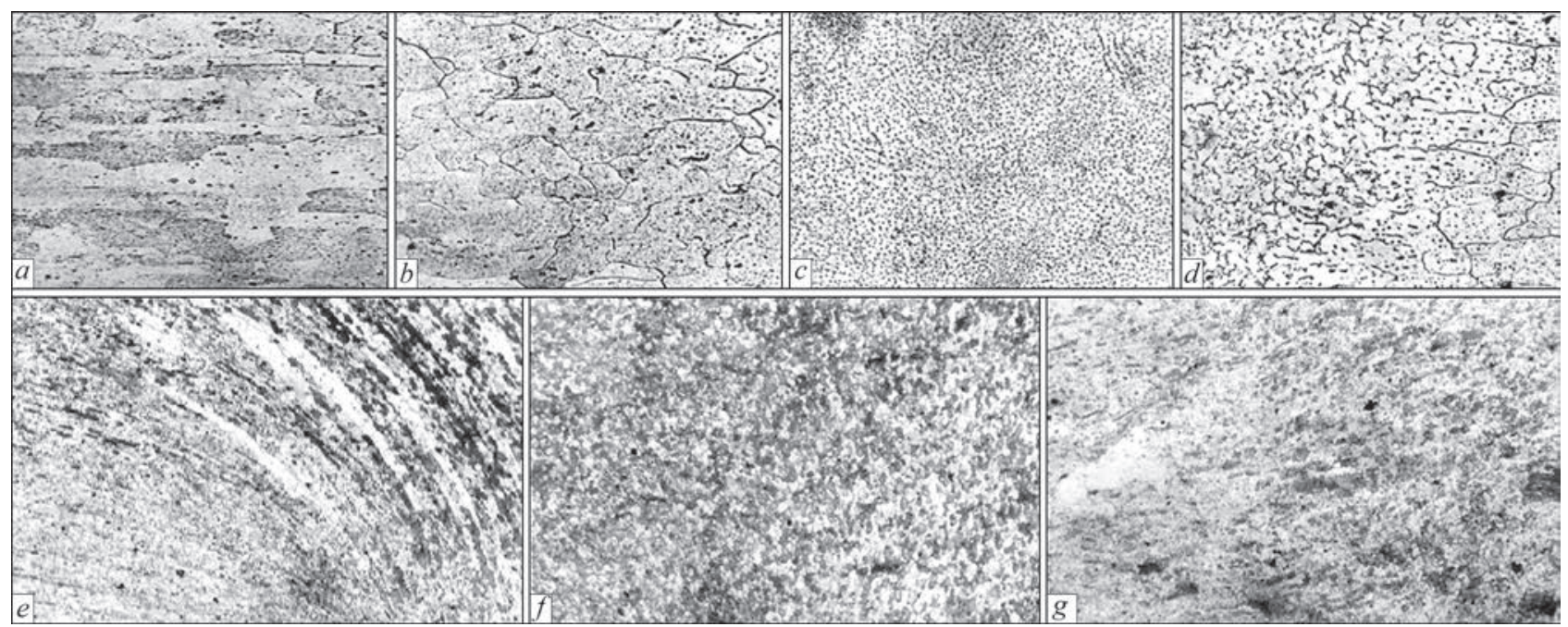

Figure 4. Microstructure $(\times 400)$ of base metal $(a)$ and welded joints of 1460 alloy $2 \mathrm{~mm}$ thick, produced by TIG welding with application of Sv1201 filler wire $(b, d$ - zone of weld fusion with base metal; $c$ - weld) and by FSW ( $d$ - thermomechanical impact zone from the tool advancing side; $f$ - weld nugget; $g$ — thermomechanical impact zone from the tool retreating side)

fail in the weld metal and have minimum ultimate strength of $257 \mathrm{MPa}$. Fracture of samples with weld reinforcement proceeds in the zone of weld fusion with base material. Samples of FS-welded joints fail in the zone of thermomechanical impact. Here, their ultimate strength is on the level of $310 \mathrm{MPa}$, similar to samples with weld reinforcement made by TIG welding with Sv1201 wire. At application of a strip of 1460 base material as filler wire, ultimate strength of samples with weld reinforcement is equal to $297 \mathrm{MPa}$ on average.

Lowering of metal heating temperature in the zone of permanent joint formation at FSW has a positive effect on the level of residual stresses. In TIG welding of 1420 alloy the maximum value of residual longitudinal stresses is on the level of $99 \mathrm{MPa}$ (Figure 7). At about $16 \mathrm{~mm}$ distance from weld axis, they drop to zero, and further on compressive stresses develop with maximum value of $29 \mathrm{MPa}$ at $35 \mathrm{~mm}$ distance. In FS-welded joints, maximum value of tensile stresses is equal to just $64 \mathrm{MPa}$. Maximum value of residu-

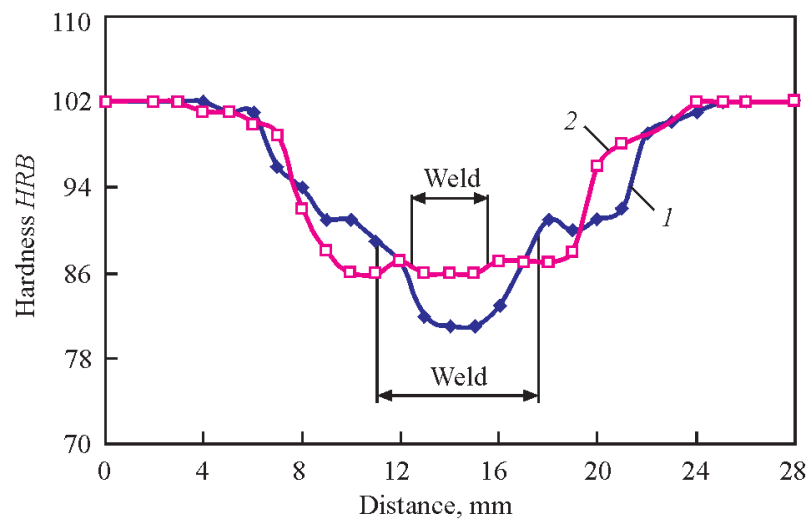

Figure 5. Hardness distribution on the surface of welded joints of 1420 alloy $1.8 \mathrm{~mm}$ thick (here and in Figures 6 and 7: 1 TIG-welded; 2 - FS-welded joint) al compressive stresses at $35 \mathrm{~mm}$ distance from weld axis decreases to $22 \mathrm{MPa}$, respectively.

Experimentally established fatigue curves of butt FS-welded joints of 1420 and 1460 aluminium alloys demonstrate high values of fatigue resistance. Limited endurance limit of FS-welded joints of 1420 alloy is lower by $10-15 \%$ than the respective values for base metal in the entire range of fatigue life of $10^{5}-2 \cdot 10^{6}$ cycles of stress reversal (Figure 8). For 1460 alloy the respective values of limited endurance limit are by

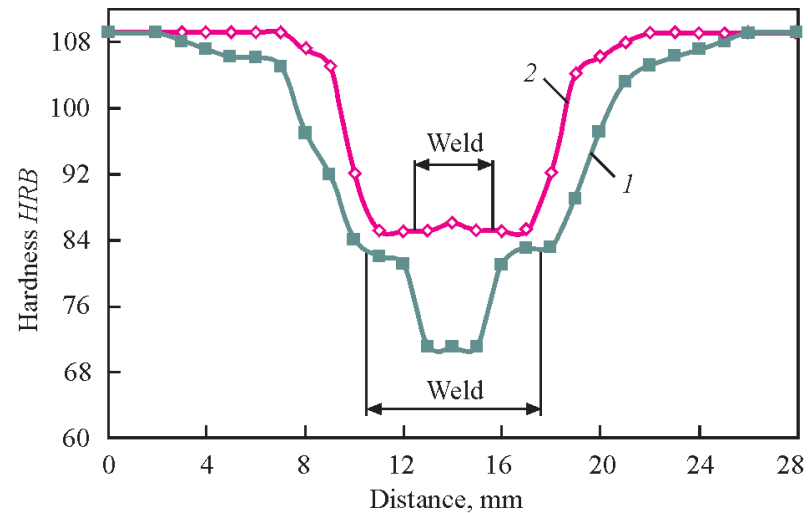

Figure 6. Hardness distribution on the surface of welded joints of 1460 alloy $2 \mathrm{~mm}$ thick

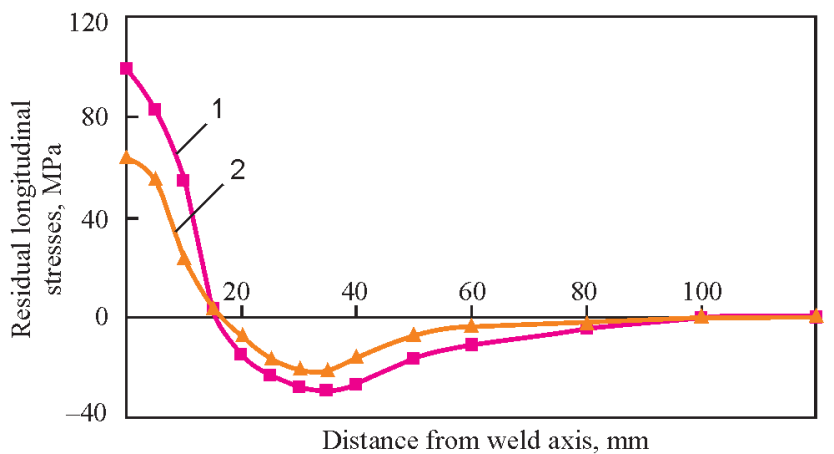

Figure 7. Distribution of residual longitudinal stresses in welded joints of 1420 alloy $1.8 \mathrm{~mm}$ thick 


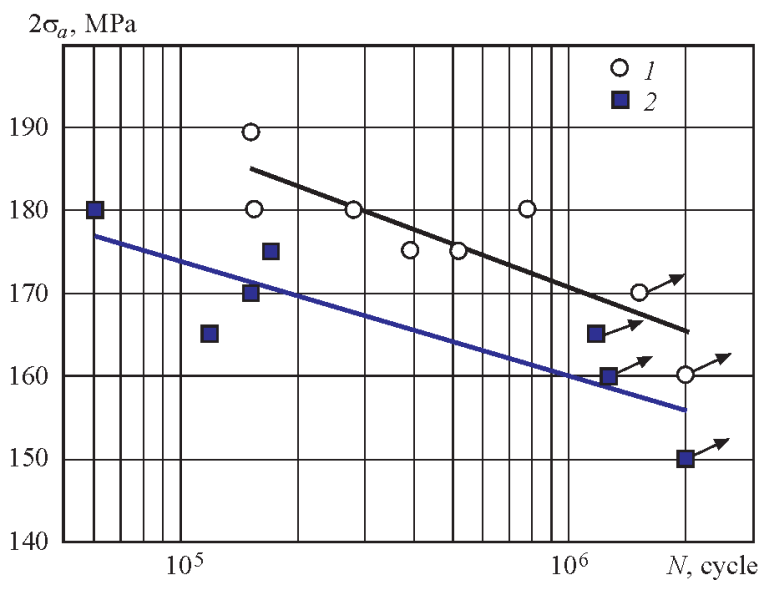

Figure 8. Fatigue curves of base metal (1) and FS-welded joints (2) of alloy $14201.8 \mathrm{~mm}$ thick at stress cycle asymmetry $R_{\sigma}=0.1$ 20-25\% lower than those of base metal (Figure 9). For FS-welded joints of 1420 and 1460 alloys the values of limit ranges of stresses on the base of $2 \cdot 10^{6} \mathrm{cy}-$ cles are equal to 155 and $120 \mathrm{MPa}$, respectively. Limit range values for TIG-welded joints of 1460 alloy on the base of $2 \cdot 10^{6}$ cycles of stress reversal are equal to $85 \mathrm{MPa}$ that is by $30 \%$ lower than the respective value for joints, made by FSW.

\section{Conclusions}

1. FSW application provides a permanent joint with minimum level of stress concentration in the points of transition from the weld to base material, and allows avoiding defects in welds in the form of pores and macroinclusions of oxide film due to metal melting and solidification in fusion welding.

2. Formation of permanent joint in the solid phase at FSW allows avoiding coarse-dendrite structure of welds characteristic for fusion welding. Here, refinement of base metal grains and formation of new homogeneous disoriented structure with 3-4 $\mu \mathrm{m}$ grain size and dispersed $(\leq 1 \mu \mathrm{m})$ phase precipitates occur around the tool tip, where the metal is the most exposed to thermomechanical impact. Near the weld nugget in the thermomechanical impact zone, a combined structure forms, which consists of fine equiaxed and deformed thin elongated grains, oriented along the direction of tool displacement.

3. At FSW of heat-hardenable Al-Li alloys 1420 and 1460 the thermomechanical impact, in addition to grain refinement in the welding zone, promoting increase of metal hardness, results in simultaneous partial precipitation of excess phases from oversaturated solid solution and their coagulation, that leads to a certain lowering of joint hardness. However, the degree of metal softening in solid-phase welding of 1420 and 1460 alloys is much smaller than in fusion welding. Therefore, ultimate strength of FS-welded

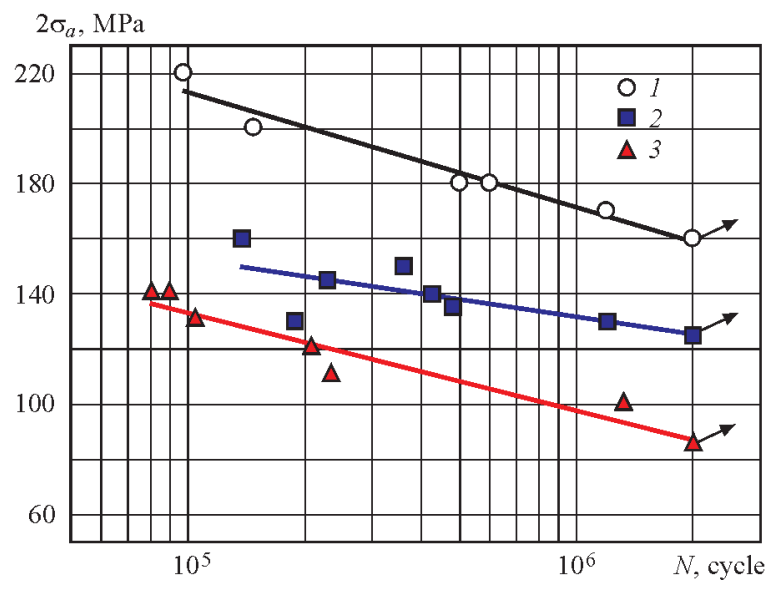

Figure 9. Fatigue curves of base metal (1), FS- (2) and TIG-welded (3) joints of 1460 alloy $2 \mathrm{~mm}$ thick at stress cycle asymmetry $R_{\sigma}=0.1$

joints of these alloys is higher than that of TIG-welded joints without weld reinforcement.

4. As a result of weld formation in the solid phase at lower temperatures, compared to fusion welding, the maximum level of tensile residual longitudinal stresses in welded joints of 1420 alloy, produced by FSW, is by $35 \%$ lower than that in TIG welding.

5. Proceeding from experimental data of fatigue testing, the rationality of application of FSW process instead of TIG welding in fabrication of structures with Al-Li alloys 1420 and 1460, operating under alternating loading conditions, was substantiated. It is established that fatigue resistance characteristics of butt welded joints, made by FSW technology, are higher than the respective values of TIG-welded joints. Values of limit stress ranges based on $2 \cdot 10^{6} \mathrm{cy}-$ cles of stress reversal for FS-welded joints are just by 10-20\% lower than those of base material.

1. Beletsky, V.M., Krivov, G.A. (2005) Aluminium alloys (composition, properties, technology, application)n: Refer. Book. Ed. by I.N. Fridlyander. Kiev: KOMINTEKh.

2. (2002) Aircraft materials: Transact. of VIAM 1932-2002, 424. Moscow: MISIS VIAM.

3. Bratukhin, A.G. (2003) Modern aircraft materials: Technological and functional peculiarities. Moscow: Aviatekhinform.

4. Rabkin, D.M., Lozovskaya, A.V., Sklabinskaya, I.E. (1992) Metals science of aluminium and its alloys. Kiev: Naukova Dumka.

5. Mashin, V.S., Poklyatsky, A.G., Fedorchuk, V.E. (2005) Mechanical properties of aluminium alloys in consumable and nonconsumable electrode arc welding. The Paton Welding J., 9, 39-45.

6. Thomas, W.M., Nicholas, E.D., Needham, J.C. et al. Friction stir butt welding. Int. Pat. Appl. PCT/GB 92/02203; GB Pat. Appl. 9125978.8. Publ. 1991.

7. Defalco, J. (2006) Friction stir welding vs. fusion welding. Welding J., 3, 42-44.

8. Ericsson, M., Sandstrom, R. (2003) Influence of melting speed on the fatigue of friction stir welds and comparison with MIG and TIG. Int. J. Fatigue, 25, 1379-1387.

9. Enomoto, M. (2003) Friction stir welding: Research and industrial applications. Welding Int., 5, 341-345.

10. Ishchenko, A.Ya., Poklyatsky, A.G. Tool for friction stir welding of aluminium alloys. Pat. 54096 Ukraine. Int. Cl. B23K 20/12. Fil. 30.04.2010. Publ. 25.10.2010.

Received 28.03.2016 